\title{
Environmentally friendly biopositive design protection of water intake facilities' urban water management systems
}

\author{
Elguja Khetsuriani ${ }^{1,2^{*}}$, Vladimir Bondarenko ${ }^{3}$, Teona Khetsuriani ${ }^{1}$, and Timur \\ Khetsuriani $^{2,4}$ \\ ${ }^{1}$ M. I. Platov South Russian State Polytechnic University (NPI), 346400 Novocherkassk, Russia \\ ${ }^{2}$ Don State Technical University, 344000 Rostov-on-Don, Russia \\ ${ }^{3}$ Novocherkassk Engineering and Land Reclamation Institute named after A.K. Kortunov FSBEI HE \\ Don State Agrarian University, 346428 Novocherkassk, Russia \\ ${ }^{4}$ Rostov State Medical University, 344022 Rostov-on-Don, Russia
}

\begin{abstract}
The article presents structural and technological solutions in the revision of the constructive paradigm that has been in effect for many decades, associated with the use of traditional structural materials (metal, concrete, reinforced concrete) in the creation of various types of protective devices for water intakes of urban water management systems. The paper notes that the currently existing various types of water intake structures made of traditional materials do not meet modern requirements for environmental acceptability indicators and, accordingly, cannot provide the necessary environmental safety. As a result of the conducted research, an environmentally safe bio positive design for protecting the water intake structure of urban water management systems in the form of a soft floating structure made of high-strength synthetic fabric materials, is proposed. Calculations of structural elements of a soft surfaced structure are given.
\end{abstract}

\section{Introduction}

In the development of a new methodological approach, it became necessary to revise the constructive paradigm that has been in effect for many decades, associated with the use of traditional structural materials (metal, concrete, reinforced concrete) in the construction and operation of various types of water intake structures for urban water management systems. It should be noted that the currently operating various types of water intake facilities built from traditional materials do not meet modern requirements in terms of environmental acceptability (EA) and, accordingly, cannot provide the necessary environmental safety [24].

As a result of our research to provide EA, we adopted a new structural material in the form of a high-strength synthetic fabric, which is widely used in the construction of transformable structures for various functional purposes, in individual structural elements and the structure as a whole of the water intake structure as part of the urban water management system. For water intake structures of urban water management systems, high-

\footnotetext{
* Corresponding author: goodga@mail.ru
} 
strength synthetic fabric materials, as shown by the results of the study, are used in the creation of protective devices in the form of soft floating structures (SFS) (Figure 1), which are located in the design section of the water intake complex water body (Figure 2), taking into account the water flow hydraulic structure [6].

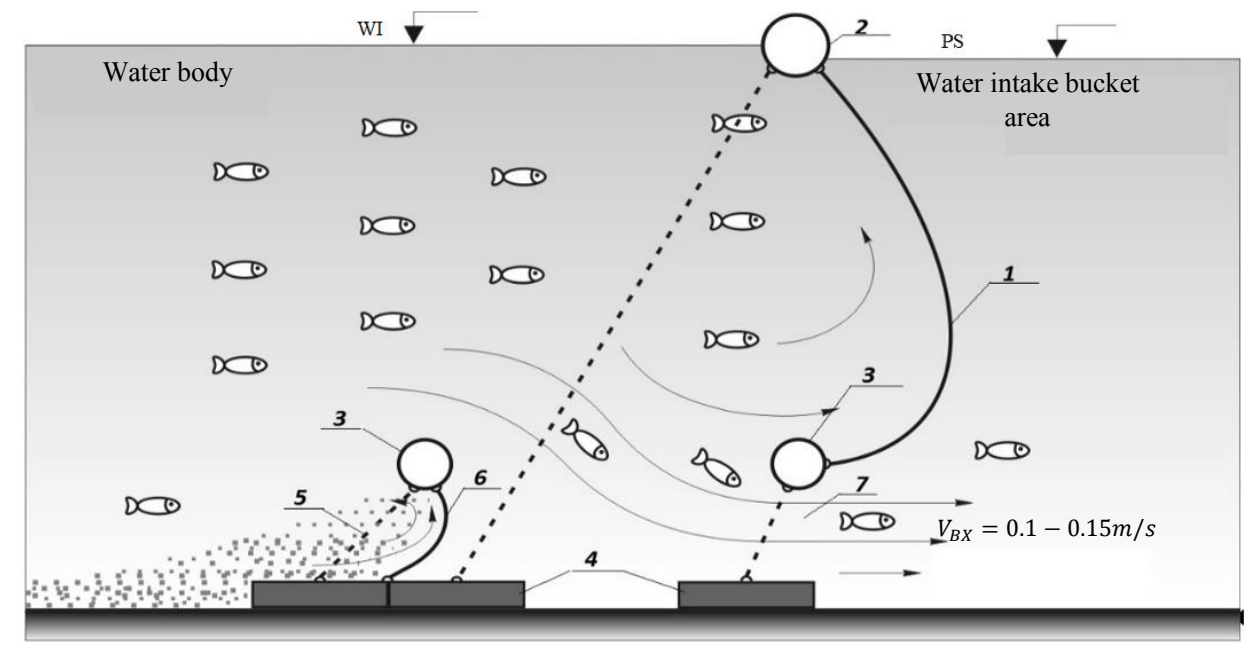

Fig. 1. Soft floating structure of the water intake structure of the city water management system 1flexible screen of a given shape along the water flow depth; 2 -system of surface floats; 3 systems of recessed floats; 4- anchor devices; 5- flexible connections; 6- recessed flexible screen; 7- water intake window

SFS of the water intake structure includes a movable flexible screen placed at the water flow depth in the calculated coastal section of the water body, the upper edge of which is attached to the surface floats system (2) and the lower edge to the system of buried floats (3), which are held in the planned placement on the water surface and at depth by anchor devices (4) with flexible connections (5). A recessed flexible screen (6) is placed at a certain distance from the water intake window (7), which performs the function of diverting bottom species of ichthyofauna and sediment from the water intake window, in which the water flow rate $v$, based on the physical characteristics of the ichthyofauna, should not exceed $0,1 \mathrm{~m} / \mathrm{s}$. 


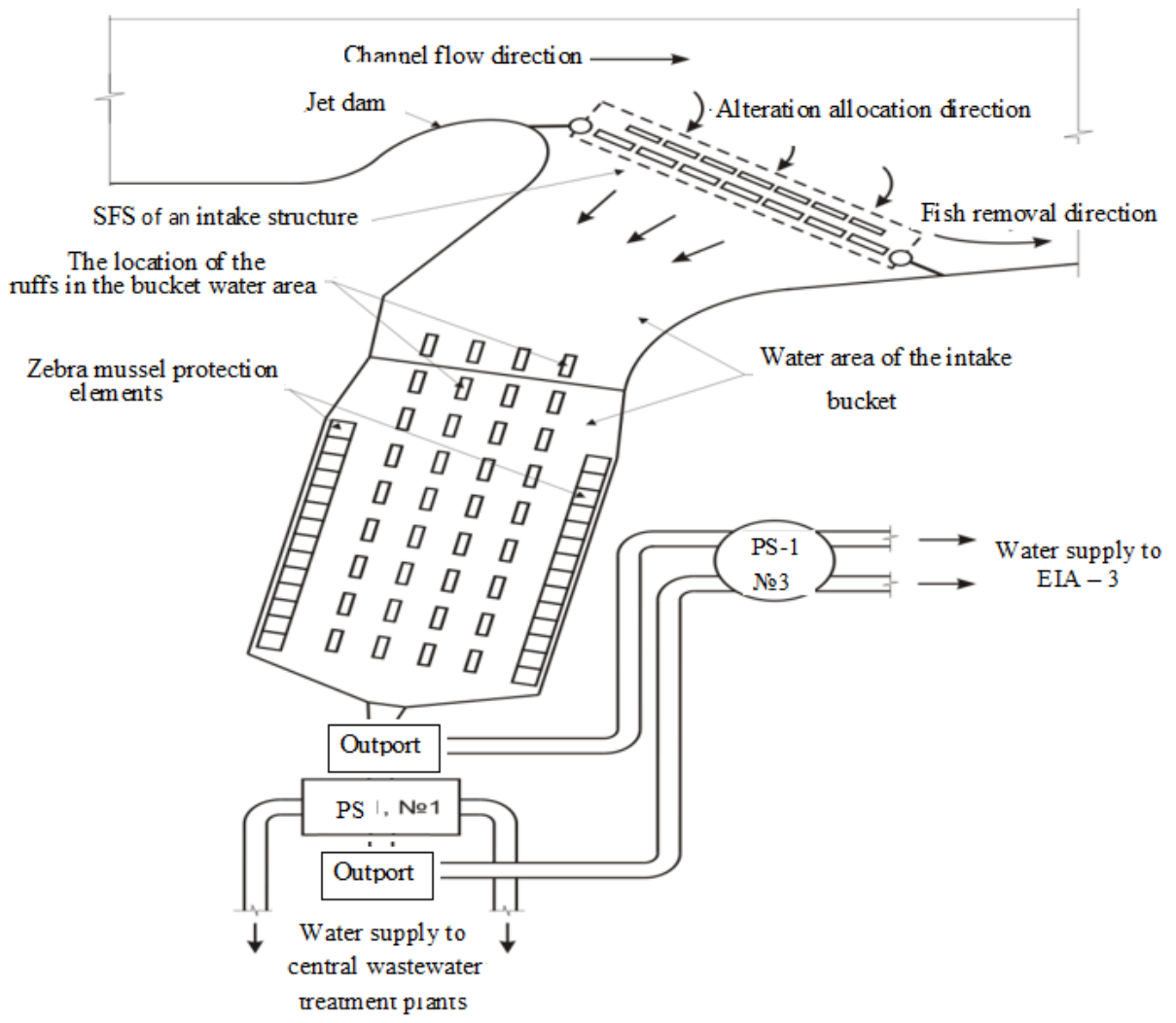

Fig. 2. Water supply system water intake complex of the cities of Rostov-on-Don, Aksai, Bataysk.

\section{Materials and methods}

The studies have found that SFS of the city water management system water intake structure has a number of structural and functional advantages over the water intake structures made of traditional materials. The most important advantage indicators are:

- high level of ecological acceptability to the natural environment [1-3];

- multifunctionality associated with ensuring the ichthyofauna and aquatic vegetation biodiversity preservation in a water body, protection of the water intake bucket from bottom and suspended sediments, sludge and floating objects coming from the water body [12-13];

- the possibility of the structure quick installation and dismantling;

- fairly low weight and high transportability;

- ample opportunities in automation and control, etc.

For SFS water intake structures as part of urban water management systems and economic facilities, three basic structural elements have been developed (see Fig. 1): a flexible screen that blocks the upper layers of the water flow (1); a flexible screen blocking the water flow lower (bottom) layers (6); a flexible screen that blocks the entire depth of the water flow in the form of a blank structure with interfacing the coastal abutments [6].

To ensure stable SFS functional performance of the water intake structure, important design elements are the determination of hydrostatic, hydrodynamic pressure and wave 
loads on the flexible screen, based on the results of which the flexible screens soft shell calculation is performed.

\section{Research results}

When selecting the estimated water flow through the bottom water intake window (see Fig. 1), the total hydrostatic and velocity head of the water flow is determined by the formula:

$$
Z_{0}=\frac{v^{2}}{2 g M^{2}}
$$

where $\mathrm{M}$ is the flow coefficient for a flooded hole with smooth lateral approaches $\mathrm{M}=0,8$ 0,$85 ; v$ is the speed of the water flow approach to the structure (Fig. 3).

Specific consumption (q) water withdrawal in the water intake window is determined by the formula:

$$
q=m \sqrt{2 g} H^{3 / 2}
$$

where $m-$ is a flow coefficient for a flooded spillway, determined by the Bazin formula:

$$
m=\left(0,405-\frac{0,0027}{H}\right) \cdot 1,05\left(1+0,2 \frac{H-Z}{\rho}\right) \cdot \sqrt{Z / H}
$$

where $H-$ defines water pressure on the weir foot board.

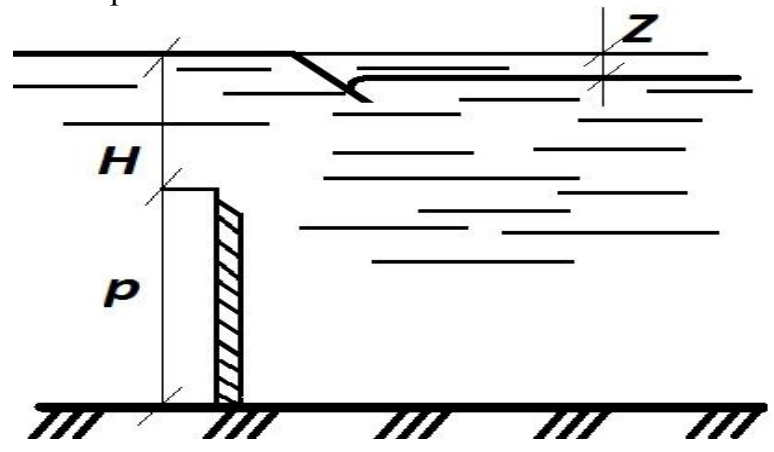

Fig. 3. Design scheme for determining $Z$

Determination of the $Z$ drop is reduced to solving a nonlinear equation in an implicit form with respect to :

$$
q=\left[\left(0,405-\frac{0,0027}{H}\right) \cdot 1,05\left(1+0,2 \frac{H-Z}{\rho}\right) \cdot \sqrt{\frac{Z}{H}}\right] \cdot \sqrt{2 g} H^{3 / 2}
$$

The total head on the flexible screen consists of the static differential WI and PS (Fig. 1) $Z$ and high-speed pressure $\frac{v^{2}}{2 g M^{2}}$.

The wave load from wind and ship waves on a flexible screen (1) can be determined taking into account the velocity head of water particles, where the relative velocity is taken into account in the calculation $\mathrm{v}_{r e l}$ of the flexible screen shell element $\mathrm{v}_{s h}$ and water $\mathrm{v}_{\text {wat }}$, 
projected onto the normal $\bar{n}$ shell element (Fig. 4). High-speed pressure from the wave $P^{\text {wav }}$ is determined:

and taking into account the direction

$$
P^{w a v}=\frac{v_{r e l} \cdot \bar{n}}{2 g}
$$

$$
\begin{aligned}
& P^{w a v}=\frac{\left|\overline{\mathrm{v}_{\text {rel }}} \cdot \bar{n}\right| \mathrm{v}_{\text {rel }} \cdot \bar{n}}{2 g} \\
& \mathrm{v}_{\text {rel }}=\mathrm{v}_{w a t}-\mathrm{v}_{s h}
\end{aligned}
$$

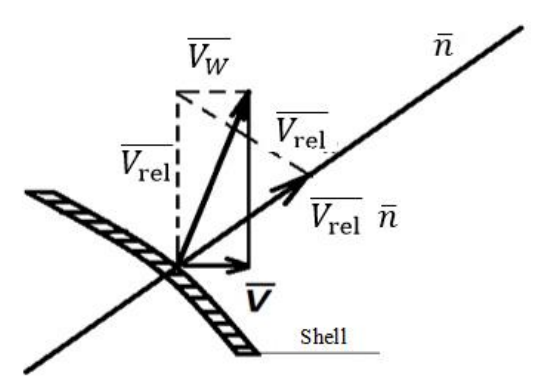

Fig. 4. Vector diagram of speeds

In real conditions there are mainly progressive waves on water bodies, therefore, it is recommended to determine the speed of water particles by the dependencies:

$$
\begin{aligned}
& \mathrm{v}_{Z}^{w a t}=C e^{k z} k \cos (\sigma t+k x) \\
& \mathrm{v}_{Z}^{w a t}=k C e^{k z} \sin (\sigma t+k x)
\end{aligned}
$$

where $\sigma-$ is angular velocity; $k=\sigma^{2} / g-$ is a wave number; $C=a g /$ - is a constant of integration; $a-$ is a wave amplitude; $\mathrm{x}$ and $\mathrm{z}$ are the coordinates of water points; $t$ determines time.

The speed of the flexible screen shell elements for each moment of time is determined by the formula:

$$
\mathrm{v}_{x i}^{s h}=\frac{d x_{t}^{s h}}{d t} ; \quad \mathrm{v}_{z i}^{s h}=\frac{d z_{t}^{s h}}{d t}
$$

where $v_{x i}^{s h}$ and $\mathrm{v}_{z i}^{s h}-$ define the displacement of the flexible screen shell $\mathrm{i}$-th element in time $d t$ in the $\mathrm{X}$ and $\mathrm{Z}$ direction respectively.

The calculation is performed by a numerical method according to the program developed by us for LBM (computer software).

\section{Methodology for calculating SFS structural elements}

Based on the results of SFS theoretical research, a flexible screen of bio positive tissue materials is considered as a cylindrical shell. The calculation of the cylindrical shell is carried out on the basis of solving a system of linear equations in accordance with the design scheme (Fig. 5 a). 

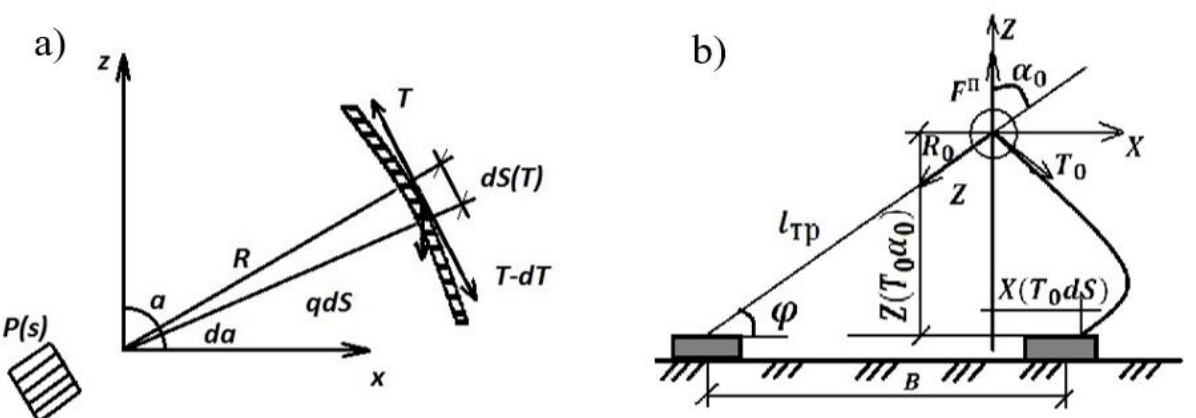

c)

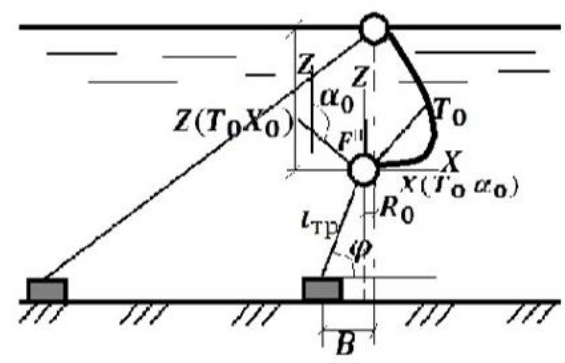

Fig. 5. a- calculation scheme for drawing up differential equations; b-design scheme for a deep flexible screen; $\mathrm{c}$ - design scheme for flexible screen (1)

$$
\left\{\begin{array}{c}
d s=\frac{d(T \cos \alpha) \cos \alpha}{P \cdot \sin \alpha} \\
d z=\frac{d(T \sin \alpha) \sin \alpha}{P \cdot \cos \alpha-q} \\
d s=\frac{T d \alpha}{P}
\end{array}\right.
$$

The solution of the system of equations (15) taking into account the nonlinearity of functional dependencies $\mathrm{p}=\mathrm{f}(\mathrm{s}) ; \mathrm{ds}=\mathrm{f}(\mathrm{T})$ is carried out according to the developed program for computer software.

The engineering calculation is based on the breakdown of the soft shell into a finite number of interconnected elements. The procedure for calculating the $\mathrm{i}$-th element of the shell flexible screen is performed in the sequence:

$$
\begin{gathered}
T_{i+1}=T_{i}-q_{0}\left(Z_{i}+\Delta S_{i} \frac{\sin \alpha_{i}}{2}\right) \\
\Delta S_{i+1}=\frac{l_{s c}\left(T_{i}\right)}{n} \\
\Delta \alpha=P\left(Z_{i}+\Delta S_{i} \frac{\sin \alpha_{i}}{2}\right) \\
\Delta \alpha=\alpha_{i}+\Delta \alpha \\
X_{i+1}=X_{i}+\Delta S_{i} \cos \alpha_{i+1} \\
Z_{i+1}=Z_{i}+\Delta S_{i} \sin \alpha_{i+1}
\end{gathered}
$$


where q0- is a linear weight of the screen-shell; Ti- defines the effort in the i-th element; $\Delta S_{i}$ - is a step along the length of the shell; $l_{s c}\left(T_{i}\right)$ - is the shell screen length (perimeter in height); $\alpha, \Delta \alpha-$ define the current angle and increment by angle; $\mathrm{Xi}, \mathrm{Zi}, \mathrm{Zi}+1, \mathrm{Xi}+1$ are the coordinates of the ends of the element. The calculation is carried out according to the program compiled for IBM and computer software.

Definition of T0 effort and starting angle $\alpha_{0}$ is performed by the Newton-Kantorovich method, in which the procedure for calculating the screen-shell is divided into two functions:

$$
\left\{\begin{array}{l}
X_{-} s c\left(T_{-} 0 \cdot \alpha_{-} 0\right)=D \\
Z_{-} s c\left(T_{0} \cdot \alpha_{0}\right)=N
\end{array}\right.
$$

where $\mathrm{D}$ - is an offset by $\mathrm{X}$ between the top and bottom crumb of the shell screen; $\mathrm{P}$ - is an excess of the upper edge over the lower granulates.

For the case when the position of the upper edge and the lower edge of the flexible screen-shell depends on the surface buoyancy force and the buried float systems Fn, function of the load $\mathrm{p}(\mathrm{z})$, the "parameters" equations for $\mathrm{X}$ and for $\mathrm{Z}$ are drawn up, and the acting factor should be "tied" in the intake structure geometric parameters' definition. So, to compose a system of equations for calculating the bottom recessed flexible screen (Fig. 5, b), the equilibrium equations for the system of recessed floats are drawn up (Figure 5, b)

$$
\left\{\begin{array}{c}
F p=R_{f r} \cdot \sin \varphi+T_{0} \cdot \sin \alpha_{0} \\
R_{f r} \cdot \cos \varphi=T_{0} \cdot \cos \alpha_{0}
\end{array}\right.
$$

Where does the angle value come from $(\varphi)$ is determined by the formula:

$$
\varphi=\operatorname{arctg}\left(\frac{F^{P}-T_{0} \sin \alpha_{0}}{T_{0} \cos \alpha 0}\right)
$$

and the equations of the "Perimeters" will be written as:

$$
\left\{\begin{array}{c}
f_{1}^{\prime \prime}=X\left(T_{0} \alpha_{0}\right)-B+l_{f r} \cdot \cos \varphi=0 \\
f_{2}=X\left(T_{0} \alpha_{0}\right)-l_{f r} \cdot \cos \varphi
\end{array}\right.
$$

Similar equations for the perimeters will be when calculating a vertical screen panel with a system of surface, recessed floats and flexible connections (Fig. 1 (1))

Calculation of forces in the fabric screen-panel is carried out taking into account the hydrostatic and hydrodynamic effects of wave loads.

The calculation is performed using the limit state method, i.e., the greatest effort should not exceed its bearing capacity:

$$
T \leq \frac{\gamma_{c d} \cdot R}{\gamma_{n} \cdot \gamma_{i c}}
$$

where T- is the greatest design effort; $\gamma_{c d^{-}}$is a working condition factor; $\gamma_{n}{ }^{--}$is a load combination ratio; $R$ - is the bearing capacity of the float system.

The design force in the fabric material of the screen-panel is determined by the expression: 
where $\mathrm{Tn}-\cdot$ is a normative force in flexible screen fabric, $\mathrm{kN} / \mathrm{m} ; \mathrm{K} 0=0,7-0,8-$ is a material homogeneity coefficient; Kdur $=0,-0,9$ - durability factor; $\mathrm{Kt}=0,80-0,95$ is a temperature coefficient; $K d y n=0,80-0,95$ is a dynamic coefficient; $K s s=0,80-0,95$ is a seam strength factor; Kw.c. is a working condition factor.

To ensure operational reliability, the emerging forces in the fabric flexible screen are recommended to be reduced in the range from 2 to 7 times [6].

Based on the research results and operating experience of a structure made of fabric materials, the system of surface and buried floats is recommended to be performed from steel electric-welded longitudinal seam pipes (GOST 10704-76 Art. SEL 490-77).

At the design stage, the perimeter of the vertical screen (Lv.s.) is constructively defined by the expression:

$$
L_{V . S .}=Z \cdot K_{p}+a+h b / 2
$$

where Z- is the height of the water flow surface layer (Fig.5.c) is determined by the difference in the marks of the surface and buried floats' systems; $\mathrm{Kr}$ - is a design factor, taken in the range of 1.5-1.6; $a$ - is determined constructively adopted depending on the fluctuation of water levels in a water body during the operation of the intake structure; $h$ - is wind wave height on a water body $5 \%$ of availability or wave height from river vessels.

Working perimeter of the recessed auxiliary flexible screen (b) (Fig. 5b) is constructively defined by the expression:

$$
L_{R . F .}=(1.4-1.5) h_{w}
$$

where $h_{w^{-}}$is the intake window height.

The spatial arrangement of the buried bottom flexible screen (Fig. 1) relative to the vertical movable screen panel is determined by the distance (B), which is taken from the conditions of the required hydraulic structure of the flow in front of the water intake window for the removal of juvenile bottom fish species, bottom sediments and is within $(1,75-2,5) h_{w}$.

\section{Calculation of flexible connections and anchor devices}

The studies have established that the maximum stresses in flexible bonds occur under wave loads on the system of surface floats (Fig. 1). Estimation of wave loads on the SFS intake structure is carried out in accordance with BC 2.06.04-82 «Loads and impacts on hydraulic structures "(wave, ice and from ships).

The maximum force in a flexible connection (rope) occurs at the attachment point with a surface floats system and is determined by the expression:

$$
N_{\text {max }}=\sqrt{R^{2}+\left(F_{A}-F\right)^{2}} \leq R
$$

Equation of the flexible connection form at the wave attack angle $\alpha=90$ degree. And the possibilities of disregarding its mass have the form:

$$
\left\{\begin{array}{c}
X=\frac{1}{2}\left[\operatorname{ch}\left(C_{i}\right)-\operatorname{ch}\left(\alpha z+C_{i}\right)\right] \\
l_{c \mathrm{~B}}=\frac{1}{2}\left[\operatorname{ch}\left(\alpha z+C_{i}\right) \operatorname{ch}\left(C_{i}\right)\right]
\end{array}\right.
$$

Where 


$$
C_{i}=\operatorname{lntg} \frac{Q_{b}}{q}-\alpha h
$$

For the general case $(\mathrm{q}=0, \quad \alpha \leq 2 \leq 90$ degree $\delta=\mathrm{f}(\mathrm{z})$ a program for computer software numerical calculation has been developed.

$$
N_{\text {max }}=f_{1}(h, \lambda, C, d) ; x=f_{2}(h, \lambda, C, d, z) ; l=f_{3}(h, \lambda, C, d, z)
$$

where $\mathrm{h}$ - is wave height; $\lambda$ - is wavelength; $\mathrm{C}$ - is wave speed; $\mathrm{df}$ - defines the floats diameter; $\mathrm{Z}$ - is a variable $(0 \leq \mathrm{Z} \leq \mathrm{h})$.

Anchoring devices are made of reinforced concrete in the form of slabs with loops for fastening flexible ties. Anchoring devices are held by the forces of gravity, friction against the ground and adhesion to the ground (Fig. 6).

The mass of the anchor device must be at least:

$$
G_{Q . Y .}=\frac{R\left(\cos \alpha+f_{f r} \sin \alpha\right)}{f_{f r}}
$$

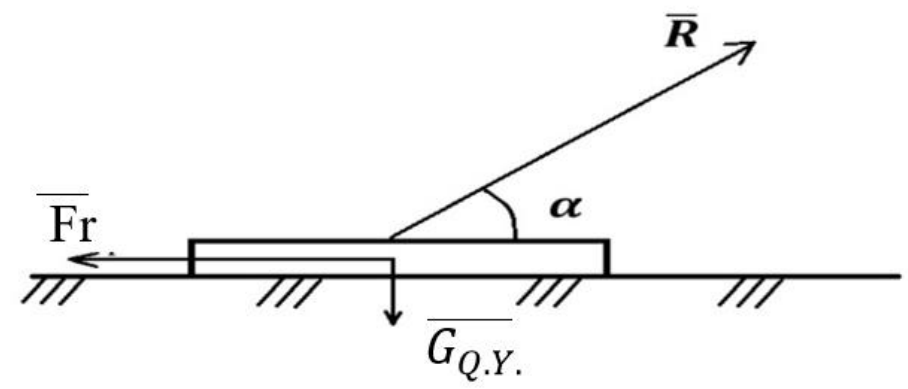

Fig.6. Design diagram of the anchor device, where $f_{f r}$ - coefficient of friction of concrete on soil; $G_{Q . Y .^{-}}$weight of anchor suspended in water

The volume of a reinforced concrete slab is determined by the formula:

$$
V_{Q . Y .}=\frac{G_{Q . Y .}}{\gamma_{c}-\gamma_{w}}
$$

where $\gamma_{c}$ - is the specific gravity of reinforced concrete, $\gamma_{c}=24-25 \mathrm{kN} / \mathrm{m} 3 ; \gamma_{w^{-}}$is the specific gravity of water $\gamma_{w}=10 \mathrm{kN} / \mathrm{m} 3$.

Concrete friction coefficient on the ground ffr in water: for loam $0,3-0,45$; for fine sand $0,4-0,55$; for coarse sand $0,5-0,7$; for gravel $0,6-0,8$.

\section{Conclusion}

- based on the structures analysis results of water intake structures made of traditional materials (metal, concrete, reinforced concrete), a low level of environmental acceptability to the environment and insufficient provision of modern environmental requirements was established;

- the use of high-strength synthetic bio positive tissue materials made it possible to create an environmentally acceptable water intake structure for the urban water management system, which makes it possible to increase the level of environmental 
protection and ensure the environmental safety of the city economy, its main criterion indicators;

- based on the results of theoretical studies of the soft floating structure of the water intake structure as part of the urban water management system, methods for calculating structural elements from bio positive tissue materials for various operating modes of the structure in interaction with the aqueous environment of the water body have been developed.

\section{References}

1. V.L. Bondarenko, A.I. Ylyasov, E.D. Khetsuriani, monograph Scientific and methodological foundations of natural-technical systems in the use of water resources: territories of basin geosystems (Novocherkassk, 2019)

2. V.L. Bondarenko, G.M. Skibin, V. N. Azarov, E.A. Semenova, V.V. Privalenko; Environmental safety in environmental management, water use and construction: assessment of the ecological state of basin geosystems: Monograph (NPI, Novocherkassk, 2016)

3. V.L. Bondarenko, E.A. Semenova, A.V. Aliferov, O.V, Klimenko, Natural and technical systems in the use of water resources: territories of basin geosystems: monograph (NPI, Novocherkassk, 2016)

4. V.L. Bondarenko, V.B. Dyachenko, Problems of regional ecology 2, 86-92 (2005)

5. M.I. Budyko, O.A. Drozdov, About moisture turnover in a limited land area. Questions of hydrometeorological efficiency of field protection afforestation (Gidrometeoizdat, L., 1950)

6. V.A. Volosukhin, V.L. Bondarenko, Building systems for the protection of water resources using the structures from fabric materials: monograph (Colorit, Novocherkassk, 2008)

7. K.S. Losev, Environmental problems and prospects for sustainable development of Russia in the XXI century (Kosmosinform, M., 2001)

8. A.M. Chernyaeva, River basins (Publishing house Agroecology, Yekaterinburg, 1999)

9. E.D. Khetsuriani, V.P. Kostyukov, E.G. Ugrovatova, Hydrological research on the river Don in Aleksandrovsky WWS Water intake facilities. Procedia techniques 150 (2nd International Conference on Industrial Engineering, ICIE 2016) May 192016 , Chelyabinsk, Russia (2016)

10. E.D. Khetsuriani, T.E. Khetsuriani, measures will be taken to combat the eutrophication of water bodies priority tasks and strategies for the development of agricultural science: Sat. science tr (international Scientific practical Conference FTSNiO EVENSIS) May 25, 2016, Tolyatti, Russia (2016)

11. E.D. Khetsuriani, L.N. Fesenko, A.N. Bogachev, M.M. Mordvinuev, G.N. Puras, A. Yu. Dushenko, R.S. Bechvaya, A.V. Pelcher, Engineering Journal of Don 4 (2015)

12. E.D. Khetsuriani, V.P. Kostyukov, T.E. Khetsuriani, IOP Conference Series: Materials Science and Engineering 262 (2017)

13. E.D. Khetsuriani, V.L. Bondarenko, N.A. Polyansky, IOP Conference Series: Materials Science and Engineering 262 (2018)

14. E.D. Khetsuriani, V.L. Bondarenko, A.I. Ylyasov, E.A. Semenova, The results of the research on the pipelines protection from Zebra mussle on the water intake technological complexes of multi-purpose water supply systems for urban farms, IOP 
Conference Series: Materials Science and Engineering 698, 055041 (2019). International Scientific Conference "Construction and Architecture: Theory and Practice of Innovative Development" 1-5 October 2019, Kislovodsk, Russia https://iopscience.iop.org/article/10.1088/1757-899X/698/5/055041/pdf

15. E.D. Khetsuriani, V.L. Bondarenko, A.I. Ylyasov, E.A. Semenova, Lightweight constructions in technical water supply systems of thermal and nuclear power plants, IOP Conference Series: Materials Science and Engineering 698, 055042 (2019). International Scientific Conference "Construction and Architecture: Theory and Practice of Innovative Development" 1-5 October 2019, Kislovodsk, Russia https://iopscience.iop.org/article/10.1088/1757-899X/698/5/055042/pdf

16. E.D. Khetsuriani, V.L. Bondarenko, A.I. Ylyasov, E.A. Semenova, Innovative design solutions to ensure the environmental safety in the existing water intake technological complexes of water systems for urban farms, IOP Conference Series: Materials Science and Engineering 698, 055040 (2019). International Scientific Conference "Construction and Architecture: Theory and Practice of Innovative Development" 1-5 October 2019, Kislovodsk, Russia. https://iopscience.iop.org/article/10.1088/1757899X/698/5/055040/pdf

17. E.D. Khetsuriani, V.L. Bondarenko, A.I. Ylyasov, E.A. Semenova, Development of protective measures providing environmental safety in areas affected by water-intake constructions of urban households, IOP Conference Series: Materials Science and Engineering 698, 077053 (2019). International Scientific Conference "Construction and Architecture: Theory and Practice of Innovative Development" 1-5 October 2019, Kislovodsk, $\underline{899 X / 698 / 7 / 077053 / \mathrm{pdf}}$ https://iopscience.iop.org/article/10.1088/1757- 